\title{
Human Endogenous Retroviruses (HERVs) and Autoimmune Rheumatic Disease: Is There a Link?
}

\author{
Nicola Tugnet ${ }^{*}$, , Paul Rylance ${ }^{2}$, Denise Roden ${ }^{3}$, Malgorzata Trela $^{3}$ and Paul Nelson ${ }^{3}$ \\ ${ }^{I}$ Department of Rheumatology, Royal Wolverhampton Hospitals NHS Trust, Wolverhampton, UK \\ ${ }^{2}$ Department of Nephrology, Royal Wolverhampton Hospitals NHS Trust, Wolverhampton, UK \\ ${ }^{3}$ Molecular Immunology Research Group, Research Institute in Healthcare Science, University of Wolverhampton, UK
}

\begin{abstract}
Autoimmune rheumatic diseases, such as RA and SLE, are caused by genetic, hormonal and environmental factors. Human Endogenous Retroviruses (HERVs) may be triggers of autoimmune rheumatic disease. HERVs are fossil viruses that began to be integrated into the human genome some 30-40 million years ago and now make up $8 \%$ of the genome. Evidence suggests HERVs may cause RA and SLE, among other rheumatic diseases. The key mechanisms by which HERVS are postulated to cause disease include molecular mimicry and immune dysregulation. Identification of HERVs in RA and SLE could lead to novel treatments for these chronic conditions. This review summarises the evidence for HERVs as contributors to autoimmune rheumatic disease and the clinical implications and mechanisms of pathogenesis are discussed.
\end{abstract}

Keywords: Human endogenous retrovirus, HERV, rheumatoid arthritis, molecular mimicry, bioinformatics.

\section{INTRODUCTION}

Over the last three decades there has been an interest in human endogenous retroviruses (HERVs) as potential contributors towards autoimmune disease, made all the more important given that the incidence of autoimmunity is increasing worldwide [1]. Endogenous retroviruses (ERVs) and other retroviral elements have been found in all vertebrates investigated [2]. Much work has been done to elucidate the numerous retroviral families that exist within the human genome, of which ERVs make up 8\% [3]. HERVs are believed to be pathogenic in several autoimmune diseases, but especially the rheumatic diseases such as rheumatoid arthritis (RA) and systemic lupus erythematosus (SLE) $[4,5]$. The growing body of evidence suggests RA and SLE are complex diseases which require genetic susceptibility, environmental factors and opportune circumstances operating together to induce disease [6]. Previous studies have explored the possibility of induction of SLE by Epstein - Barr virus (EBV) and HERVs [7-9].

The aim of this review is to summarise the existing evidence for the role of HERVs in autoimmune rheumatic disease, focussing specifically on RA and SLE. This paper describes several hypotheses on the mechanisms by which HERVs are thought to be pathogenic. This is important as the link between HERVs and rheumatic disease could lead to the discovery of novel therapeutic agents - and even cures for these chronic diseases.

\footnotetext{
*Address correspondence to this author at the Department of Rheumatology, New Cross Hospital, Wednesfield Road, Wolverhampton, WV10 0QP, UK; Tel: (+44) 1902 695492; Fax: (+44) 1902 695736;

E-mail: ntugnet@doctors.org.uk
}

\section{HERVS: ORIGIN AND CLASSIFICATION}

Retroviruses are small viruses which replicate by reversing the normal flow of genetic information from DNA to RNA, known as reverse transcription. Exogenous retroviruses such as human immunodeficiency virus (HIV) and human $\mathrm{T}$ cell leukaemia virus (HTLV) can reproduce viral RNA from their pro-viral DNA, and hence retain infectivity, a feature lost by HERVs. HERVs were first integrated into the human genome 30-40 million years ago and are believed to be the key molecular link between the host genome and exogenous viral particles $[10,11]$. Over millions of years, HERVs (coined "fossil viruses") have become trapped within the human genome. They are transmitted genetically in a Mendelian fashion and are found within the DNA of all cells. HERVs have similar gene structures to exogenous retroviruses, and are composed of gag, pol, and env regions sandwiched between two long terminal repeats (LTRs) (see Fig. 1) [12].

\begin{tabular}{|l|l|l|l|l|}
\hline LTR & gag & pol & env & LTR \\
\hline
\end{tabular}

Fig. (1). Structure of human endogenous retroviruses (HERVs). HERV products may be generated using different open reading frames (ORFs)

LTRs are sequences of DNA that repeat hundreds or thousands of times and are used by viruses to insert their genetic sequences into the host genomes. Gag is a polyprotein and is an acronym for Group Antigens; pol is the reverse transcriptase; and env is the envelope protein that determines viral tropism. Retroviral transcription is regulated by promoter and enhancer regions in the LTR present at both ends of the retroviral genome. 
Over 26 families of HERVs have been identified [3] and, although most are defective through mutation and deletion signals, a small number have the ability to produce viral products [12]. The HERV-K family is the only family of HERVs that is able to produce intact viral particles. It is one of the most transcriptionally active families as its members retain intact open reading frames (ORFs) that encode viral particles [13]. HERVs have been broadly classified into three categories, based on their genetic similarity in the pol region (see Table 1).

Table 1. Classification of Human Endogenous Retroviruses (HERVs). Adapted from Nelson [4] and Balada [5]

\begin{tabular}{|c|c|c|}
\hline Class I & Class II & Class III \\
\hline $\begin{array}{l}\text { Group 1: HERV-HF } \\
\text { HERV-H (RTVL-H, RGH) HERV-F }\end{array}$ & $\begin{array}{l}\text { Group 1: HML-1 } \\
\text { HERV-K (HML-1.1) }\end{array}$ & HERV-L \\
\hline $\begin{array}{l}\text { Group 2: HERV-RW } \\
\text { HERV-W HERV-R (ERV9) } \\
\text { HERV-P (HuERS-P, HuRRS-P) }\end{array}$ & $\begin{array}{l}\text { Group 2: HML-2 } \\
\text { HERV-K10 } \\
\text { HERV-K-HTDV }\end{array}$ & $\begin{array}{l}\text { HERV-S } \\
\text { (HERV18) }\end{array}$ \\
\hline $\begin{array}{l}\text { Group 3: HERV-ER1 } \\
\text { HERV-E (4-1, ERVA, NP-2) } \\
\text { 51-1 HERV-R (ERV3) RRHERV-1 }\end{array}$ & \begin{tabular}{|l|} 
Group 3: HML-3 \\
HERV-K (HML3.1)
\end{tabular} & HERV-U \\
\hline $\begin{array}{l}\text { Group } 4 \text { : HERV-T } \\
\text { HERV-T (S71, CRTK1, CRTK6) }\end{array}$ & $\begin{array}{l}\text { Group 4: HML-4 } \\
\text { HERV-K-T47D }\end{array}$ & HERV-U3 \\
\hline $\begin{array}{l}\text { Group 5: HERV-IP } \\
\text { HERV-I (RTVL-I) } \\
\text { HERV-IP-T47D (ERV-FTD) }\end{array}$ & $\begin{array}{l}\text { Group 5: HML-5 } \\
\text { HERV-K-NMWV2 }\end{array}$ & \\
\hline $\begin{array}{l}\text { Group 6: HERV-FRD } \\
\text { ERV-FRD }\end{array}$ & $\begin{array}{l}\text { Group 6: HML-6 } \\
\text { HERV-K (HML-6p) }\end{array}$ & \\
\hline \multirow[t]{4}{*}{ Other: HRES-1 } & $\begin{array}{l}\text { Group 7: HML-7 } \\
\text { HERV-K-NMWV7 }\end{array}$ & \\
\hline & $\begin{array}{l}\text { Group 8: HML-8 } \\
\text { HERV-K-NMWV3 }\end{array}$ & \\
\hline & $\begin{array}{l}\text { Group 9: HML-9 } \\
\text { HERV-K-NMWV9 }\end{array}$ & \\
\hline & $\begin{array}{l}\text { Group 10: HML-10 } \\
\text { HERV-KC4 }\end{array}$ & \\
\hline
\end{tabular}

Class I contains HERVs related to Gammaretroviruses; class II viruses are related to Betaretroviruses; while Class III viruses are related to Spumaviruses [5]. Confusingly, some HERVs are known by several names, for example, HERV-K10 is also known as HML-2. A complete database of HERVs can be found online (http://herv.img.cas.cz/). It should also be noted that mobile genetic elements that behave as HERVs, such as LINE-1, have been implicated in RA [14]. LINE-1 is a DNA sequence that can change its relative position within the genome of a single cell, leading to phenotypically significant mutations. However, LINE-1 is not thought to be a true HERV by some authors as it has no LTR.

\section{BIOINFORMATICS AND HERV RESEARCH}

Bioinformatics is a rapidly-growing interdisciplinary field which harnesses computer science, mathematics, physics and biology to capture and interpret biological data [15]. Bioinformatic computer programmes can provide information about HERV protein sequences that are structurally similar (have sequence homology) to known antigenic epitopes (epitope recognition) [16]. For example, bioinformatics has been used to demonstrate that HERVK10 shares sequence homology with epitopes of rheumatoid factor (RF) [17] (Fig. 2 and Table 2), implicating molecular mimicry (see section on "Molecular mimicry"). Short peptides that reflected these epitopes were then synthesized and an enzyme-linked immunosorbent assay (ELISA) was used to test their reactivity to patient serum. This demonstrated significant up-regulation of HERV-K mRNA levels in RA patients compared to inflammatory and healthy controls. Other molecular techniques can be used to harness HERV proteins, including: immunoblot, ELISA, nucleic acid sequence-based amplification (NASBA), polymerase chain reaction (PCR), multiplex $\mathrm{PCR}$ and quantitative reverse transcription-polymerase chain reaction (RT-PCR) (see Table 3). It is beyond the scope of this article to look at these in detail but it is prudent to point out that quantitative RTPCR provides a highly sensitive technique to detect even a very low amount of RNA, found in all HERVs. Furthermore, antigen microarray profiling in RA can provide diagnostic information and allow stratification of patients with early RA into disease subsets [20].

\section{ROLE OF HERVS IN DISEASE}

Autoimmune diseases are complex diseases, whereby genetic background confers susceptibility to disease onset, but is neither sufficient nor causative for disease development [21]. The role of HERVs in disease pathogenesis is not confined to rheumatic disease, for example, it is known that expression of HERV-Fcl is increased in patients with active multiple sclerosis [22] while in psoriatic lesions, HERV sequences of the $\mathrm{W}, \mathrm{K}$ and $\mathrm{E}$ families are expressed and a new variant of the ERV9/HERV-W family has been characterized [23].

The importance of genetics in the pathogenesis of autoimmune disease is supported by their clustering in families [24]. In RA and SLE a concordance rate in monozygotic twins of only $15 \%$ [25] and $25 \%$ [26] respectively is seen, emphasizing the importance of environmental factors upon the susceptibility to autoimmune disease. Genetic susceptibility might explain why only a subgroup of individuals will develop autoimmunity after infections [24]. Moreover, genome-wide analyses in lupusprone mice have shown that major histocompatibility complex (MHC)-linked and multiple non-MHC-linked genetic factors contribute to the overall susceptibility and progression of SLE [27].

Retroviruses have been repeatedly discussed as etiological factors of autoimmune rheumatic diseases and antibodies to gag and $e n v$ regions of retroviruses, including HERVs, have been reported in patients with autoimmune disease [28-31], but the role of retroviruses in these diseases remains unclear. It is known that autoimmune rheumatic disease is more prevalent in countries where retroviral infection is endemic, for example, HTLV in Japan and Central America [32, 33]. Furthermore, the observation that other types of chronic arthritis occur with an increased prevalence in HIV-1-infected individuals also lends weight to this assumption [34]. In a pivotal study of 23 patients it was demonstrated that $45 \%$ of synovial tissues obtained from patients with RA were positive for HTLV-1 p19 and p24 
A NGQP (HERV-K10)

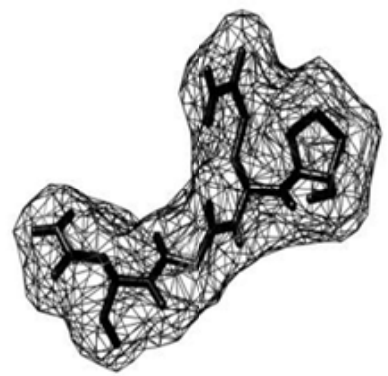

B

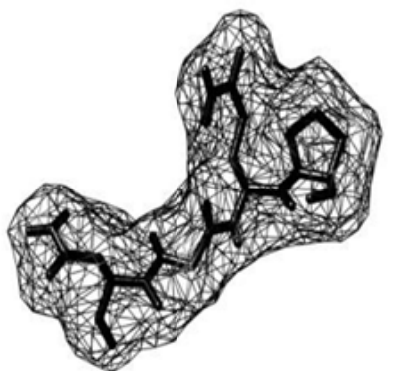

TPEVT

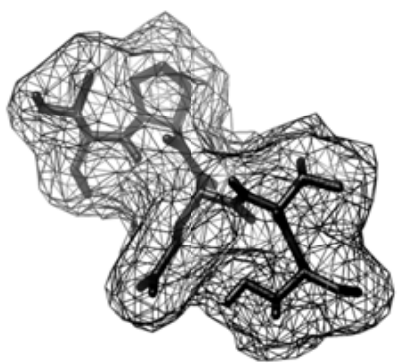

IgG1Fc CH3

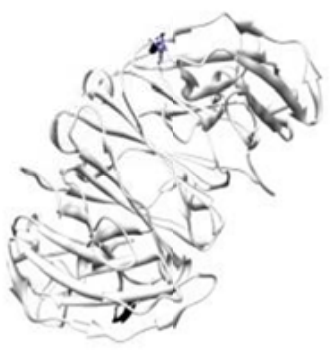

IgG1Fc CH2

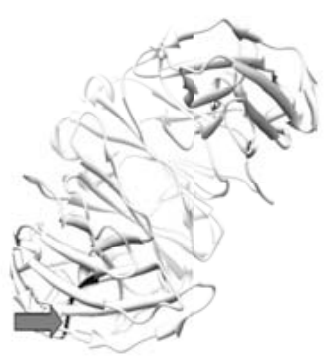

Fig. (2). Molecular models of HERV-K10/IgG1Fc epitopes. Epitopes A and B taken from Westwood [18] and modeled using PyMOL (Molecular Graphics System, Version 1.2r3pre, Schrodinger, LLC: http://www.pymol.org/pymol) and enhanced using UCSF Chimera (http://www.cgl.ucsf.edu/chimera). Molecular models were displayed in 'mesh' mode. Arrows point to amino acid residues highlighted and displayed on an IgGFc molecule (PDB file: 3AVE) using UCSF Chimera. CH: constant heavy 2 and 3 domains of IgG. In B: despite the amino acid substitution, there appears to be little change in molecular shape which may facilitate antibody cross-reactivity.

antigens but, intriguingly, no antibodies to HTLV-1 were detected in the sera [35]. In addition, another study showed $55 \%$ of patients with RA had p17 and p24 HIV antigens in synovial tissues but, yet again, their sera tested negative for antibodies to HIV [36]. It was therefore likely that an alternative retrovirus, with sequence homology to HTLV-1 (in the former) or HIV-1 (in the latter), was the cause of the immune response. Other studies revealed that SLE patients make antibodies to p24 gag of HIV-1 and that anti-Sm antibody can cross-react with p24 gag [37, 38]. Moreover, HRES-1 (Human T-cell lymphotropic virus-related Endogenous Sequence) is a HERV sequence capable of protein expression, and is expressed in higher quantities in patients with varying autoimmune disease than healthy controls [39, 40]. Thus, HERVs have been implicated as contributors to autoimmune rheumatic disease. Several studies have since demonstrated evidence of increased HERV presence in autoimmune rheumatic disease, summarized in Table $\mathbf{3}$.

\section{Clinical Significance}

There are potential therapeutic implications of HERVs acting as triggers for autoimmune rheumatic disease. There has been one small experimental study in 16 Sjogren's syndrome (SJS) patients who were randomized to receive placebo or lamivudine, a reverse transcriptase inhibitor, usually harnessed as part of Highly-Active Antiretroviral Therapy (HAART) for HIV patients [41]. This experimental treatment was given on the basis of observations that the incidence of diffuse infiltrative lymphocytosis syndrome (DILS) has significantly reduced since HAART has been introduced [42]. DILS is an SJS-like illness that affects HIVinfected individuals. There was no significant difference in outcomes in this study but the small numbers may mean the study was not powered adequately. Furthermore, retroviral infections usually require combination treatment so lamivudine therapy on its own may not be effective. There are case reports of successful treatment of autoimmune rheumatic disease complications with antiviral therapy [43] but large-scale studies are needed. Of further interest is data which revealed the HRES-1 LTR is transactivated by HIV, suggesting a potential interaction between these exogenous and endogenous retroviruses. HIV stimulates expression of HRES-1/Rab4 which, in turn, abrogates recycling of CD4 to the cell surface, leading to down-regulation of CD4 expression in HIV-infected CD4+ T-cells [44, 45]. 
Table 2. Preliminary Alignment of HERV-K10 with IgG1Fc

\begin{tabular}{|l|l|l|}
\hline \multicolumn{1}{|c|}{ HERV-K10/Autoantigen } & \multicolumn{1}{|c|}{ Bioinformatic Alignment Capsid/Nucleocapsid } & \multicolumn{1}{c|}{ Viral Envelope } \\
\hline \hline HERV-K10 & 370 -NGQP & 3 -TPEAT \\
\hline IgG1Fc & 160 -NGQP & $92-\mathrm{TPEVT}$ \\
\hline Alignment Score & $4 / 4$ & $4 / 5$ \\
\hline Replacement Score & & -12 \\
\hline
\end{tabular}

Key Rheumatoid Factor Epitopes on IgG1Fc:

$\begin{array}{ll}\text { 256-TPEVTCVVVDVSHED-270 } & \text { segment of } \mathrm{f} \times 2 \text { face and } \mathrm{b} 2 \text { bend of } \mathrm{CH} 2 \text { domain } \\ \text { 382-ESNGQPENNYKTTPP-396 } & \mathrm{b} 3 \text { bend and segment } \mathrm{f} \times 3 \text { face of } \mathrm{CH} 3 \text { domain }\end{array}$

Epitopes taken from Westwood [18]. Numerals indicate amino acid position and sequence alignment (LALIGN software (http://www.ch.embnet.org/software/LALIGN form.html)) with reference to protein accession numbers: HERV-K10 Gag2 (Capsid and Nucleocapsid) (AAA88031.1), Pol/Env (AAA88033.1), IgG Fc (AF150959). Residues highlighted in bold indicate amino acid substitutions. Alignment score shown as number of identical residues/number in peptide segment. Amino acid replacement score taken from Tudos [19]. Amino acid single letter code: $\mathrm{G}=$ Glycine, $\mathrm{A}=\mathrm{Alanine}, \mathrm{S}=\mathrm{Serine}, \mathrm{T}=$ Threonine, $\mathrm{C}=$ Cysteine $\mathrm{V}=$ Valine, $\mathrm{D}=\mathrm{A}$ sparate, $\mathrm{E}=\mathrm{Glutamate} \mathrm{N}=\mathrm{Asparagine}, \mathrm{Q}=\mathrm{Glutamine}, \mathrm{P}=\mathrm{Proline}$, $\mathrm{K}=$ Lysine, $\mathrm{H}=$ Histidine, $\mathrm{Y}=$ Tyrosine. Despite a low scoring amino acid replacement for $\mathrm{A}$ to $\mathrm{V}$, the overall molecular shape could remain similar enough to enable antibody crossreactivity.

Table 3. Summary of Studies Implicating HERVs in Autoimmune Rheumatic Disease and Molecular Techniques Used in Each

\begin{tabular}{|c|c|c|c|c|}
\hline Disease & HERV & Study & Molecular Technique & Significance/Result \\
\hline \multirow{7}{*}{ RA } & $\begin{array}{l}\text { HTLV-1 p19 and HIV } \\
\text { p24 antigens }\end{array}$ & Ziegler et al. $[35,36]$ & Western blot, ELISA & $\begin{array}{l}45-55 \% \text { patients expressed HTLV- } 1 \text { antigen in synovial } \\
\text { tissue, without serological HTLV-1 infection }\end{array}$ \\
\hline & HERV-K10 & Nelson et al. [31] & Quantitative RT-PCR & $\begin{array}{l}\text { Significant association of sequence homology between } \\
\text { HERVs and autoimmune rheumatic diseases }\end{array}$ \\
\hline & HERV-K10 & Reynier et al. [13] & NASBA & $\begin{array}{l}\text { HERV-K detected in plasma of RA patients, with higher } \\
\text { levels observed for those with active disease. }\end{array}$ \\
\hline & HERV-K10 & Ejtehadi et al. [46] & Multiplex RT-PCR & Enhanced expression of HERV-K10 in RA \\
\hline & $\begin{array}{l}\text { HERV-K10 } \\
\text { HERV-W (MSRV) } \\
\text { ERV-9 }\end{array}$ & Nakagawa et al. [49] & RT-PCR & $\begin{array}{l}\text { Multiple HERVs were expressed in normal and diseased } \\
\text { synovium }\end{array}$ \\
\hline & HERV-K10 & Friemanis et al. [17] & $\begin{array}{l}\text { Quantitative RT-PCR, } \\
\text { ELISA }\end{array}$ & $\begin{array}{l}\text { RA patients exhibited significantly elevated levels of } \\
\text { HERV-K gag activity compared to controls }\end{array}$ \\
\hline & HERV-K113 & $\begin{array}{l}\text { Krzysztalowska- } \\
\text { Wawrzyniak et al. }[47]\end{array}$ & PCR & $\begin{array}{l}\text { Significantly increased prevalence of HERV-K113 in } \\
\text { patients with SLE and RA }\end{array}$ \\
\hline \multirow{6}{*}{ SLE } & HRES-1 & Banki et al. [39] & Western blot, ELISA & $\begin{array}{l}\text { Sera from patients with autoimmune disease had increased } \\
\text { HRES-1 peptide binding activity than controls. }\end{array}$ \\
\hline & HRES-1 & Perl et al. [63] & Western blot, ELISA & $\begin{array}{l}\text { Autoantibodies to HRES-1 found in autoimmune disease, } \\
\text { especially if Ro / La negative. }\end{array}$ \\
\hline & HRES-1 & Pullman et al. [69] & Southern blot, PCR & $\begin{array}{l}\text { The HRES- } 1 \text { locus at the } 1 \mathrm{q} 42 \text { chromosomal region } \\
\text { influences SLE development and disease manifestations }\end{array}$ \\
\hline & HIAP-1 & Deas et al. [72] & $\begin{array}{l}\text { Polyacrylamide gel } \\
\text { electrophoresis } \\
\text { (PAGE) }\end{array}$ & Cells exposed to HIAP-1 may be protected from apoptosis. \\
\hline & $\begin{array}{l}\text { HTLV-1 p19 and HIV } \\
\text { p24 antigens }\end{array}$ & Talal et al. $[37-38]$ & Western blot & $\begin{array}{l}\text { Antibodies to p24 gag of HIV-1 found in absence of HIV-1 } \\
\text { infection. Anti-Sm antibodies can cross-react with p24 gag. }\end{array}$ \\
\hline & ERV-3 & Li et al. [30] & Western blot, ELISA & $\begin{array}{l}\text { ERV- } 3 \text { may have a role in the pathogenesis of neonatal } \\
\text { congenital heart block. }\end{array}$ \\
\hline JIA & HERV-K18 & Sicat et al. [82] & $\begin{array}{l}\text { Semi-quantitative RT- } \\
\text { PCR }\end{array}$ & $\begin{array}{l}\text { HERV-K18 levels elevated suggesting a mechanism for } \\
\text { autoimmunity by superantigen stimulation of auto-reactive } \\
\text { T cells. }\end{array}$ \\
\hline \multirow{3}{*}{ SJS } & HIAP-1 & Garry et al. [73] & PCR & $\begin{array}{l}\text { HIAP-1 detected in cells exposed to salivary tissue from } \\
\text { patients with Sjögren's syndrome. }\end{array}$ \\
\hline & HRES-1 & Brookes et al. [40] & Northern blot, ELISA & $\begin{array}{l}\text { Significantly elevated levels of antibodies to HTLV-1 were } \\
\text { found in several diseases. }\end{array}$ \\
\hline & HERV-E env protein $(\lambda 4-1)$ & Hishikawa et al. [96] & Western blot & Anti-p30gag antibodies detected in sera of several diseases \\
\hline
\end{tabular}


Studies have also shown higher levels of HERV-K10 expression in peripheral blood and synovial fluid in RA patients $[13,17,46]$ compared with healthy controls. Higher levels of HERV expression were also observed in those with higher disease-activity scores, and hence, more active disease [13]. This may have implications for a novel biomarker in RA. Other investigators found a greater prevalence of HERV-K113 amongst RA and SLE patients; however, HERV-K113 was not associated with clinical features of disease in this study [47]. The evidence suggests that HERVs are found in greater prevalence in autoimmune rheumatic disease, which indicates a role in disease pathogenesis. Contrasting studies have shown that antibody to HERV-K10 is expressed in similar degrees in both healthy subjects and autoimmune disease [48], and that multiple HERV expression is seen in normal and diseased RA synovium [49]. Given that HERVs are incorporated into the genome, and therefore considered as self, they should not provoke an immune response. Several possible mechanisms of disease pathogenesis are described below.

\section{HERV MECHANISMS OF AUTOIMMUNE DISEASE PATHOGENESIS}

Tolerance is the process that eliminates or neutralises self-reactive immune cells [50]. Autoimmunity is caused by loss of tolerance, leading to tissue damage and destruction [51]. Tolerance is achieved in the thymus during the ontogeny of the immune system when cells that react against self are deleted (central tolerance) $[52,53]$. Some potentially self-reactive cells survive these measures and are subsequently held in abeyance (peripheral tolerance) [54]. HERV-encoded proteins should be considered as selfantigens and be tolerated by the immune system but may trigger the breakdown of tolerance.
The interaction of HERVs on the immune system is likely to be complex, particularly if associated with an autoimmune disease (Fig. 3). For the endogenous virus, mechanisms such as molecular mimicry, the role of superantigen motifs and modulation via elements within LTRs have been proposed that primarily focus on branches of the adaptive immune system (B cells plus antibodies and T cells). Undoubtedly, moieties such as RNA/DNA may also contribute via toll-like receptors (TLR's) of the innate immune system. Added to these processes, is the premise of stimulating potentially auto-reactive immune cells which have been held in abeyance through peripheral tolerance. Could this be dependent on HLA type? The breakdown of tolerance is of course a key element in autoimmunity since a number of host components may be compromised through molecular mimicry, physiochemical damage and exposure of cryptic epitopes/previously sequestered epitopes. In RA for example, IgGFc (present in all individuals) becomes a major target for autoantibodies in patients classified 'RF-positive', yet remains innocuous for those deemed 'RF- negative. Other agents such as helper viruses (e.g. EBV, cytomegalovirus (CMV)) or hormones/cytokines can also facilitate the stimulation of HERVs. Presently the role of epigenetics further compounds the situation since environmental agents may surreptitiously modulate gene expression. Consequently, the interaction of external and internal factors on HERVs at the molecular level and the generation of protein products in disrupting the immune system to effect change, damage and clinical consequence will require further research.

\section{Molecular Mimicry}

The replacement of a particular amino acid may have little effect on the overall shape of an epitope. Consequently, an antibody to virus (endogenous or exogenous) could in

\section{Schematic interactions with human endogenous retroviruses}

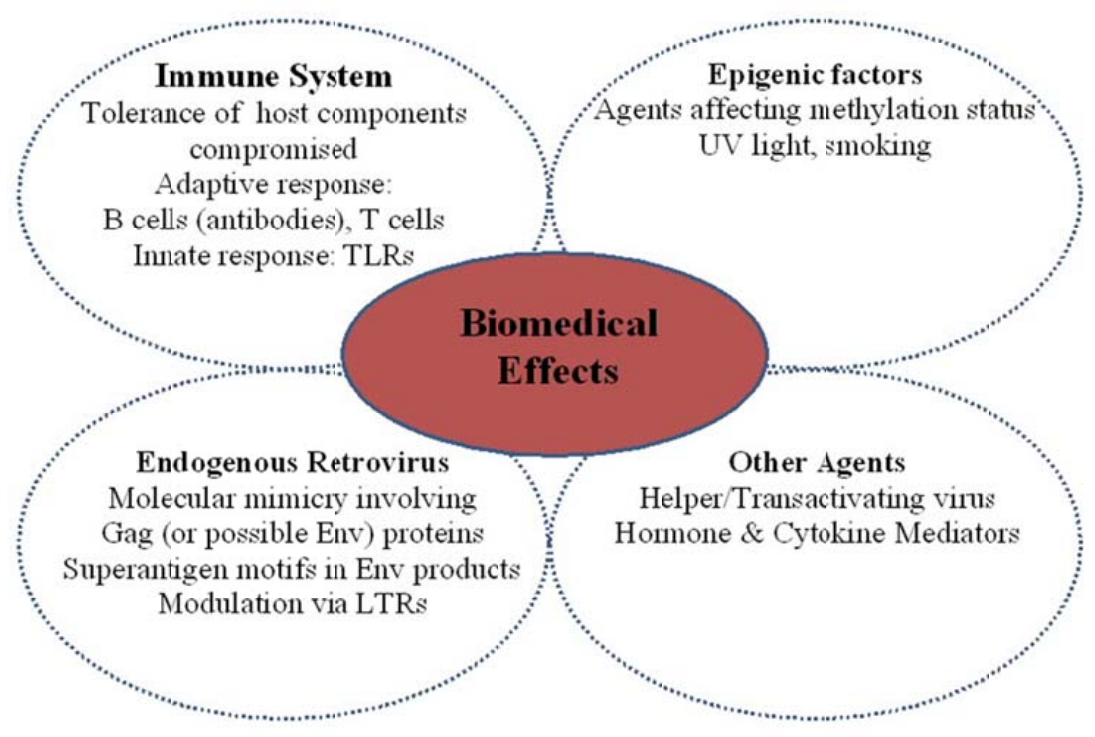

Fig. (3). Schematic interactions with human endogenous retroviruses. The interaction of HERVs on the immune system may be complex, compounded by external and internal factors to augment detrimental effects at the molecular and protein level. 
theory cross-react with a given host protein. This scenario would be particularly important for the premise of molecular mimicry. The theory of molecular mimicry is that foreign proteins may share sequence homology with peptides on self-reactive cells, and therefore cross-activate these cells. A variety of exogenous viruses have been implicated in autoimmune rheumatic diseases, such as EBV (RA and SLE) [9, 55-57], parvovirus B19 (RA) [58] and hepatitis C (RA) [59], where molecular mimicry is central to inducing autoimmunity. Molecular mimicry is thought to be the primary mechanism by which HERVs can generate an autoimmune response and cause disease. If an HERV is present, it provides a continual source of antigen for selfreactive immune cells. A potential example of viral molecular mimicry is CMV whose genome has evolved with its host by incorporating a series of genes that functionally mimic cellular genes [60]. CMV may lead to autoimmunity through molecular mimicry, epitope spreading, and an induced immune response to cryptic antigens not normally visible to the immune system. This molecular mimicry mechanism may lead to autoimmunity in SLE patients [61, $62]$.

HERV antigen that is genomically similar to exogenous viral antigen may cross-react with self, and therefore be directly responsible for eliciting pathological antibodies. A key example of this is in SLE, where $70 \mathrm{k} / \mathrm{U} 1$ snRNP is an autoantigen that has homology and cross-reactivity with a p30 gag protein of HRES-1 [63]. In this study, more than $50 \%$ SLE patients had anti-HRES- 1 antibodies which bound to this autoantigen, compared with $3.6 \%$ healthy patients, suggesting that the autoimmune response directed against U1snRNP was triggered by the expression of HERV protein. Similarly, elevated levels of autoantibody to ERV-3 are found in pregnant patients with SJS or SLE, and transfer of maternal anti-ERV-3 antibodies across the placenta correlates with the occurrence of congenital heart block in the developing fetus [30], which further supports the pathological role of these particular antibodies. There is also evidence that HERV expression is increased by proinflammatory cytokines, for example, interleukin-1 upregulates ERV-3 levels in cultured proximal tubular epithelial cells [64]. Therefore, not only could HERV infection trigger autoimmune rheumatic disease, but the resultant inflammation seen could lead to elevated HERV expression.

\section{Altered Gene Expression and Immune Dysregulation}

HERV infection could be both beneficial and detrimental to the host. Beneficial effects could include a role in blocking cellular receptors for viruses or ablating potential viral target cells, while harmful effects may be provision of a source of novel viral genes for recombination with exogenous viruses [65]. HERV sequences can integrate into any part of the genome and therefore may alter the structure and function of other genes. Retroviral integration within a gene may inactivate that gene whereas integration nearby may alter expression of the gene [66]. HERV-K10 has an integration site within the complement $\mathrm{C} 2$ gene, which could lead to mis-activation of the complement system [67]. Although the most pathogenic elements of HERVs are eliminated by selection, some pathogenicity may remain. HERVs could cause disease in some people and not in others due to HERV polymorphisms, as described in SLE where particular HRES-1 haplotypes exist [68]. Six inherited haplotypes of the HRES-1 locus have been defined which influence the development of SLE, one-in-particular that is a predictor for renal disease and absence of lung disease [69].

There is dysregulation of apoptosis in SLE and multiple autoantibodies exist [70] but it is unclear why so many potentially self-reactive cells survive deletion. It has been suggested that a low level of autoimmunity may be beneficial by assisting the immune system to recognize neoplastic cells by CD8+ T-cells, and thus reduce the incidence of cancer. In fact, increased survival in melanoma patients who have autoimmune disease has been demonstrated, suggesting that systemic autoimmunity may play a role in modifying the activity of established cancer [71]. Deletion of self-reactive cells via apoptosis is paramount to tolerance and evidence suggests that HERVs can modulate apoptosis. This has been demonstrated in studies involving Human Intracisternal A-type retrovirus Particles (HIAPs), which are antigenically-related to HIV and cause delayed apoptosis, and hence, prolonged foreign/self complex, enhancing the autoimmune response [72]. In a notable study, cells cultured from lip biopsies of SJS patients showed chronic infection with HIAPs [73]. Similarly, animal models have demonstrated systemic autoimmune disease in mice due to integration of an ERV within the Fas apoptosis gene, establishing a link between ERV expression, abnormal Fas expression, and autoimmune disease [74].

It is also plausible that HERVs may induce immune tolerance, as suggested by the role of syncytin in maternal immune tolerance to the fetus. Syncytin is important for placental function and has been found to derive from HERV$\mathrm{W}$ [75]. It is possible that syncytin-stimulated syncytiotrophoblast formation may assure syncytiotrophoblast survival by additional interaction with immune or apoptotic mechanisms [76].

\section{Superantigen Motifs}

Superantigens are microbial proteins that are potent activators of $\mathrm{CD} 4+\mathrm{T}$-cells, which leads to excessive production of cytokines [77]. For example, bacterial superantigens causing periodontitis have been linked to development of RA [78-80]. Viral proteins may similarly act as superantigens. It is known that RA and SLE patients carry antibody to EBV in much higher frequency [9, 55-57] and EBV could act as a helper virus to HERVs. For instance, HERV-K18 possesses superantigen activity and is activated by EBV [81]. HERV-K18 levels are elevated in patients with juvenile idiopathic arthritis, suggesting a possible mechanism for autoimmunity by superantigen stimulation of self-reactive T-cells [82].

\section{REGULATION OF HERVS VIA DNA HYPOMETHY- LATION}

Epigenetics refers to heritable changes in genes, regulating gene expression without changing the DNA sequence [10]. DNA methylation is an essential process for normal development and cellular differentiation. It consists of the addition of a methyl group to cytosine residues and helps to stabilize chromatin in an inactive configuration, thus inhibiting gene transcription [26, 83]. Hypomethylation can 
cause increased expression of given genes that are normally silenced [84]. It is thought that hypomethylation may alter synovial fibroblasts, which triggers RA development [8586]. Altered methylation has been explored in B cells [87] and $\mathrm{T}$ cells [88] while changes in the pattern of DNA methylation have been found to associate with twin discordance in SLE [89]. Murine models have clearly demonstrated reduced methylation levels in the thymus of lupus-prone mice compared to non-prone mice [90]. Several other human studies have corroborated the importance of DNA hypomethylation in SLE etiology [91-93]. Expression of HERV clone 4-1 (HERV-E family) is significantly increased in SLE patients compared with healthy controls, while serum autoantibodies to this HERV and expression of its antigens on lymphocytes are detected in SLE patients, but not in healthy subjects [83, 94-96]. Furthermore, certain drugs are known to be inhibitors of DNA methylation, such as procainamide, and when demethylating agents have been given, HERV 4-1 expression is markedly increased in healthy controls, but not in SLE patients [93], which suggests involvement of demethylation of normally methylated sequences in SLE. As yet, there is no concrete link between HERVS and hypomethylation but the possibility exists. No doubt, the expanding area of epigenetics will provide the evidence required.

\section{CONCLUSION}

This paper has reviewed the evidence for HERVs as contributors to autoimmune rheumatic disease. Progress in accrual of evidence has been slow but major advances in serological, molecular and viral load have occurred. Suggested mechanisms for disease pathogenesis include molecular mimicry, immune dysregulation and superantigen motifs. The evidence appears to be mounting for HERV-K10 in RA pathogenesis and for HRES-1 and ERV-3 in SLE, but there is a clear need for animal models to corroborate this, and a call for large multicentre studies to examine the percentage of patients that exhibit high reactivity to these viruses. This may reveal other differences between populations and different races. Toll-like receptors and their possible interaction with viral material is also an emerging area of importance in both SLE and RA, which introduces the possibility that the innate system may be involved in pathogenesis. Bioinformatic and molecular modeling studies to investigate potential molecular mimicry would similarly be useful.

Given the debilitating nature and chronicity of these conditions, prevention of autoimmune rheumatic disease is the 'holy grail'. Just as vaccination against Human Papilloma Virus is routinely given in some countries to protect females from development of cervical carcinoma, perhaps one day a similar programme may exist for those patients identified to be at high risk of developing RA (eg. individuals who are strongly RF+ and HERV-K10+). Moreover, HERV titers may one day be used as markers of disease activity or as diagnostic markers, just as RF is used today. Looking ahead, there may be a need for larger studies of antiretroviral treatment in patients with autoimmune rheumatic disease that investigate whether eliminating the viral proteins leads to disease remission. Clearly, there are numerous questions to be answered and we remain some way off this stage. National and/or international collaboration would add to the depth of quality research and help to unlock the answers within this fascinating field.

\section{CONFLICT OF INTEREST}

The authors confirm that this article content has no conflicts of interest.

\section{ACKNOWLEDGEMENTS}

Declared none.

\section{REFERENCES}

[1] Fierabracci A. Unraveling the role of infectious agents in the pathogenesis of human autoimmunity: the hypothesis of the retroviral involvement revisited. Curr Mol Med 2009; 9(9): 102433.

[2] Perl A. Role of endogenous retroviruses in autoimmune diseases. Rheum Dis Clin North Am 2003; 29: 123-43.

[3] Gifford R, Tristem M. The evolution, distribution and diversity of endogenous retroviruses. Virus Genes 2003; 26: 291-315.

[4] Nelson PN. Retroviruses in rheumatic diseases. Ann Rheum Dis 1995; 55: 441-2.

[5] Balada E, Vilardell-Tarr'es M, Ordi-Ros J. Implication of human endogenous retroviruses in the development of autoimmune diseases. Int Rev Immunol 2010; 29: 351-70.

[6] Klareskog L, Catrina AI, Paget S. Rheumatoid arthritis. Lancet 2009; 373: 659-72.

[7] Ogasawara H, Hishikawa T, Sekigawa I, Hashimoto H, Yamamoto N, Maruyama N. Sequence analysis of human endogenous retrovirus clone 4-1 in systemic lupus erythematosus. Autoimmunity 2000; 33: 15-21.

[8] Ogasawara H, Kageyama M, Yamaji K, Takasaki Y. The possibility that autoimmune disease can be induced by a molecular mimicry mechanism between autoantigen and human endogenous retrovirus. Lupus 2010; 19: 111-3.

[9] Harley JB, James JA. Epstein - Barr virus infection induces lupus autoimmunity. Bull NYU Hosp Jt Dis 2006; 64(1-2): 45-50.

[10] Blank M, Shoenfeld Y, Perl A. Cross-talk of the environment with the host genome and the immune system through endogenous retroviruses in systemic lupus erythematosus. Lupus 2009; 18: $1136-43$

[11] Sekigawa I, Ogasawara H, Kaneko H, Hishikawa T, Hashimoto H. Retroviruses and autoimmunity. Intern Med 2001; 40(2): 80-6.

[12] Nelson PN, Carnegie PR, Martin J et al. Demystified human endogenous retroviruses. Mol Pathol 2003; 56: 11-18.

[13] Reynier F, Verjat T, Turrel F et al. Increase in human endogenous retrovirus HERV-K (HML-2) viral load in active rheumatoid arthritis. Scand J Immunol 2009; 70: 295-99.

[14] Ali M, Veale DJ, Reece RJ et al. Overexpression of transcripts containing LINE-1 in the synovia of patients with rheumatoid arthritis. Ann Rheum Dis 2003; 62(7): 663-6.

[15] Bayat A. Bioinformatics: Science, medicine, and the future. BMJ 2002; 324: 1018-22.

[16] Roden D, Ejtehadi H, Rowland-Jones S et al. Use of bioinformatics to highlight antigenic regions of exogenous and endogenous retroviruses. Immunology 2001; 104: S112-3.

[17] Freimanis G, Hooley P, Ejtehadi HD et al. A role for human endogenous retrovirus-K (HML-2) in rheumatoid arthritis: investigating mechanisms of pathogenesis. Clin Exp Immunol 2010; 160: 340-7.

[18] Westwood OM, Hay FC, Eds. Epitope mapping, 1st edn. Oxford: Oxford University Press 2000.

[19] Tudos E, Cserzo M, Simon I. Predicting isomorphic residue replacements for protein design. Int J Peptide Protein Res 1990; 36: 236-9.

[20] Hueber W, Kidd BA, Tomooka BH et al. Antigen microarray profiling of autoantibodies in rheumatoid arthritis. Arthritis Rheum 2005; 52(9): 2645-55.

[21] Meda F, Folci M, Baccarelli A, Selmi C. The epigenetics of autoimmunity. Cell Mol Immunol 2011; 8(3): 226-36.

[22] Laska MJ, Brudek T, Nissen KK. Expression of HERV-Fc1, a human endogenous retrovirus, is increased in patients with active multiple sclerosis. J Virol 2012; 86(7): 3713-22. 
[23] Molès JP, Tesniere A, Guilhou JJ. A new endogenous retroviral sequence is expressed in skin of patients with psoriasis. $\mathrm{Br} \mathrm{J}$ Dermatol 2005; 153(1): 83-9.

[24] Kivity S, Agmon-Levin N, Blank M, Shoenfeld Y. Infections and autoimmunity - friends or foes? Trends Immunol 2009; 30(8): 40914.

[25] Silman AJ, MacGregor AJ, Thomson W, et al. Twin concordance rates for rheumatoid arthritis: results from a nationwide study. $\mathrm{Br} \mathrm{J}$ Rheumatol. 1993; 32(10): 903-7.

[26] Arnett FC, Reveille JD. Genetics of systemic lupus erythematosus. Rheum Dis Clin North Am 1992; 18: 865-92.

[27] Baudino L, Yoshinobu K, Morito N, Santiago-Raber ML, Izui S. Role of endogenous retroviruses in murine SLE. Autoimmun Rev 2010; 10(1): 27-34

[28] Rucheton M, Graafland H, Fanlon H, Ursule L, Ferrier P, Larsen CJ. Presence of circulating antibodies against gag-gene MuLV proteins in patients with autoimmune connective tissue disorders. Virology 1985; 144: 468-80.

[29] Krieg AM, Steinberg AD. Retroviruses and autoimmunity. J Autoimmun 1990; 3: 137-66.

[30] Li JM, Fan W, Horsfall AC, et al. The expression of human endogenous retrovirus-3 in fetal cardiac tissue and antibodies in congenital heart block. Clin Exp Immunol 1996: 104: 388-93.

[31] Nelson PN, Lever AM, Smith S, et al. Molecular investigations implicate human endogenous retroviruses as mediators of antiretroviral antibodies in autoimmune rheumatic disease. Immunol Invest 1999; 28(4): 277-89.

[32] Poiesz BJ, Poiesz MJ, Choi D. The human T-cell lymphoma/leukemia viruses. Cancer Invest 2003; 21: 253-77.

[33] Eguchi K, Origuchi T, Takashima H, Iwata K, Katamine S, Nagataki S. High seroprevalence of anti-HTLV-I antibody in rheumatoid arthritis. Arthritis Rheum 1996; 39: 463-6.

[34] Louthrenoo W. Rheumatic manifestations of human immunodeficiency virus infection. Curr Opin Rheumatol 2008; 20: 92-9.

[35] Ziegler B, Gay RE, Huang GQ, Fassbender HG, Gay S. Immunohistochemical localization of HTLVI p19- and p24-related antigens in synovial joints of patients with rheumatoid arthritis. Am J Pathol 1989; 135: 1-5.

[36] Ziegler BL, Thomas CA. Detection of HIV-1 related antigens in rheumatoid synovial tissues. Acta Histochem Cytochem 1991; 24: $1-9$.

[37] Talal N, Dauphinee MJ, Dang H, Alexander SS, Hart DJ, Garry RF. Detection of serum antibodies to retroviral proteins in patients with primary Sjogren's syndrome (autoimmune exocrinopathy). Arthritis Rheum 1990; 33: 774-81.

[38] Talal N, Garry RF, Schur PH, et al. A conserved idiotype and antibodies to retroviral proteins in systemic lupus erythematosus. J Clin Invest 1990; 85: 1866-71.

[39] Banki K, Maceda J, Hurley E et al. Human T-cell lymphotropic virus (HTLV)-related endogenous sequence, HRES-1, encodes a 28-kDa protein: a possible autoantigen for HTLV-I gag-reactive autoantibodies. Proc Natl Acad Sci USA 1992; 89: 1939-43.

[40] Brookes SM, Pandolfino YA, Mitchell TJ, et al. The immune response to and expression of cross-reactive retroviral gag sequences in autoimmune disease. Br J Rheumatol 1992; 31(11): $735-42$.

[41] Gescuk B, Wu AJ, Whitcher JP, et al. Lamivudine is not effective in primary Sjogren's syndrome. Ann Rheum Dis 2005; 64: 3261330.

[42] Panayiotakopoulos GD, Aroni K, Kyriaki D, et al. Paucity of Sjogren's-like syndrome in a cohort of HIV-1-positive patients in the HAART era. Part II. Rheumatology 2003; 42: 1164-67.

[43] Pot C, Chizzolini C, Vokatch N, et al. Combined antiviralimmunosuppressive treatment in human T-lymphotrophic virus 1Sjögren-associated myelopathy. Arch Neurol. 2006; 63(9): 131820.

[44] Nagy G, Ward J, Mosser DD, et al. Regulation of CD4 expression via recycling by HRES-1/RAB4 controls susceptibility to $\mathrm{HIV}$ infection. J Biol Chem 2006; 281: 34574-91.

[45] Perl A, Fernandez D, Telarico T, Phillips PE. Endogenous retroviral pathogenesis in lupus. Curr Opin Rheumatol 2010; 22: 483-92.

[46] Ejtehadi HD, Freimanis GL, Ali HA, et al. The potential role of human endogenous retrovirus $\mathrm{K} 10$ in the pathogenesis of rheumatoid arthritis: a preliminary study. Ann Rheum Dis 2006; 65: 612-6.

[47] Krzysztalowska-Wawrzyniak M, Ostanek M, Clark J et al. The distribution of human endogenous retrovirus $\mathrm{K}-113$ in health and autoimmune diseases in Poland. Rheumatology 2011; 50(7): 13104.

[48] Herve CA, Lugli EB, Brand A, Griffiths DJ, Venables PJ. Autoantibodies to human endogenous retrovirus-K are frequently detected in health and disease and react with multiple epitopes. Clin Exp Immunol 2002; 128: 75-82.

[49] Nakagawa K, Brusic V, McColl G, Harrison LC. Direct evidence for the expression of multiple endogenous retroviruses in the synovial compartment in rheumatoid arthritis. Arthritis Rheum 1997; 40(4): 627-38

[50] Kamradt T, Mitchison NA. Tolerance and autoimmunity. N Engl J Med 2001; 344(9): 655-64.

[51] Rashedi I, Panigrahi S, Ezzati P, et al. Autoimmunity and apoptosis - therapeutic implications. Curr Med Chem 2007; 14: 3139-51.

[52] Leech S. Molecular mimicry in autoimmune disease. Arch Dis Child 1998; 79(5): 448-51.

[53] Burnet FM. The clonal selection theory of acquired immunity, London: Cambridge University Press 1959.

[54] Schwartz RH. T cell anergy. Sci Am 1993; 269(2): 62-3, 66-71.

[55] Tosato G, Steinberg AD, Yarchoan R, et al. Abnormally elevated frequency of Epstein-Barr Virus-infected B cells in the blood of patients with rheumatoid arthritis. J Clin Invest 1984; 73: 1789-95.

[56] Balandraud N, Meynard JB, Auger I, et al. Epstein-Barr virus load in the peripheral blood of patients with rheumatoid arthritis. Arthritis Rheum 2003; 48(5): 1223-8.

[57] James JA, Kaufman KM, Farris AD, Taylor-Albert E, Lehman TJ, Harley JB. An increased prevalence of Epstein-Barr virus infection in young patients suggests a possible etiology for systemic lupus erythematosus. J Clin Invest 1997; 100(12): 3019-26.

[58] Lunardi C, Tinazzi E, Bason C, Dolcino M, Corrocher R, Puccetti A. Human parvovirus B19 infection and autoimmunity. Autoimmun Rev 2008; 8: 116-20.

[59] Agmon-Levin N, Ram M, Barzilai O et al. Prevalence of hepatitis $\mathrm{C}$ serum antibody in autoimmune diseases. J Autoimmun 2009; 32 261-6.

[60] Michelson S. Consequences of human cytomegalovirus mimicry. Hum Immunol 2004; 65(5): 465-75.

[61] Lunardi C, Bason C, Corrocher R, Puccetti A. Induction of endothelial cell damage by hCMV molecular mimicry. Trends Immunol 2005; 26(1): 19-24.

[62] Söderberg-Nauclér C. Autoimmunity induced by human cytomegalovirus in patients with systemic lupus erythematosus. Arthritis Res Ther 2012; 14: 101.

[63] Perl A, Colombo E, Dai H, et al. Antibody reactivity to the HRES1 endogenous retroviral element identifies a subset of patients with systemic lupus erythematosus and overlap syndromes. Correlation with antinuclear antibodies and HLA class II alleles. Arthritis Rheum 1995; 38(11): 1660-71.

[64] Sibata M, Ikeda H, Katumata K, Takeuchi K, Wakisaka A, Yoshoki T. Human endogenous retroviruses: expression in various organs in vivo and its regulation in vitro. Leukemia 1997; 11(Suppl 3): 145-6.

[65] Boeke JD, Stoye JP. Retrotransposons, endogenous retroviruses, and the evolution of retroelements. In: Coffin JM, Hughes SH, Varmus HE, (eds). Retroviruses. Cold Spring Harbor (NY): Cold Spring Harbor Laboratory Press 1997.

[66] Krieg AM, Gourley MF, Perl A. Endogenous retroviruses: potential etiologic agents in autoimmunity. FASEB J 1992; 6: 2537-44.

[67] Perl A. Mechanisms of viral pathogenesis in rheumatic disease. Ann Rheum Dis 1999; 58: 454-61.

[68] Magistrelli C, Samoilova E, Agarwal RK, et al. Polymorphic genotypes of the HRES-1 human endogenous retrovirus locus correlate with systemic lupus erythematosus and autoreactivity. Immunogenetics 1999; 49: 829-34.

[69] Pullmann R Jr., Bonilla E, Phillips PE, Middleton FA, Perl A. Haplotypes of the HRES-1 endogenous retrovirus are associated with development and disease manifestations of systemic lupus erythematosus. Arthritis Rheum 2008; 58: 532-40.

[70] Emlen W, Niebur JA, Kadera R. Accelerated in vitro apoptosis of lymphocytes from patients with systemic lupus erythematosus. J Immunol 1994; 152: 3685-92. 
[71] Ellerhorst JA, Cooksley CD, Grimm EA. Autoimmunity and hypothyroidism in patients with uveal melanoma. Melanoma Res 2001; 11(6): 633-7.

[72] Deas JE, Thompson JJ, Fermin CD et al. Viral induction, transmission and apoptosis among cells infected by a Human Intracisternal A-type retrovirus. Virus Res 1999; 61(1): 19-27.

[73] Garry RF, Fermin CD, Hart DJ, Alexander SS, Donehower LA, Luo-Zhang H. Detection of a human intracisternal A-type retroviral particle antigenically related to HIV. Science $1990 ; 250: 1127-9$.

[74] Wu J, Zhou T, He J, Mountz JD. Autoimmune disease in mice due to integration of an endogenous retrovirus in an apoptosis gene. $\mathrm{J}$ Exp Med 1993; 178(2): 461-8.

[75] Mi S, Lee X, Li X, et al. Syncytin is a captive retroviral envelope protein involved in human placental morphogenesis. Nature 2000; 403(6771): 785-89.

[76] Knerr B, Huppertz C, Weigel C, et al. Endogenous retroviral syncytin: compilation of experimental research on syncytin and its possible role in normal and disturbed human placentogenesis. Mol Hum Reprod 2004; 10(8): 581-8.

[77] Torres BA, Kominsky S, Perrin GQ, Hobeika AC, Johnson HM. Superantigens: The good, the bad, and the ugly. Exp Biol Med 2001; 226: 164-76.

[78] de Pablo P, Dietrich T, McAlindon TE. Association of periodontal disease and tooth loss with rheumatoid arthritis in the US population. J Rheumatol 2008; 35: 70-6.

[79] Detert J, Pischon P, Burmester GR, Buttgereit F. The association between rheumatoid arthritis and periodontal disease. Arthritis Res Ther 2010; 12: 218.

[80] Mercado FB, Marshall RI, Klestov AC, Bartold PM. Relationship between rheumatoid arthritis and periodontitis. J Periodontol 2001; 72: 779-87.

[81] Sutkowski N, Conrad B, Thorley-Lawson DA, Huber BT. EpsteinBarr virus transactivates the human endogenous retrovirus HERVK18 that encodes a superantigen. Immunity 2001; 15(4): 579-89.

[82] Sicat J, Sutkowski N, Huber BT. Expression of human endogenous retrovirus HERV-K18 superantigen is elevated in juvenile rheumatoid arthritis. J Rheumatol 2005; 32(9): 1821-31.

[83] Sekigawa I, Kawasaki M, Ogasawara $\mathrm{H}$, et al. DNA methylation: its contribution to systemic lupus erythematosus. Clin Exp Med 2006; 6: 99-106.
[84] Chen RZ, Pettersson U, Beard C, Jackson-Grusby L, Jaenisch R. DNA hypomethylation leads to elevated mutation rates. Nature 1998; 395: 89-93.

[85] Meinecke I, Rutkauskaite E, Gay S, Pap T. The role of synovial fibroblasts in mediating joint destruction in rheumatoid arthritis. Curr Pharm Des 2005; 11: 563-8.

[86] Karouzakis E, Gay RE, Michel BA, Gay S, Neidhart M. DNA hypomethylation in rheumatoid arthritis synovial fibroblasts. Arthritis Rheum 2009; 60: 3613-22.

[87] Garaud S, Le Dantec C, Jousse-Joulin S et al. IL-6 modulates CD5 expression in B cells from patients with lupus by regulating DNA methylation. J Immunol 2009; 182(9): 5623-32.

[88] Nakkuntod J, Avihingsanon Y, Mutirangura A, Hirankarn N. Hypomethylation of LINE-1 but not Alu in lymphocyte subsets of systemic lupus erythematosus patients. Clin Chim Acta 2011; 412(15-16): 1457-61.

[89] Javierre BM, Fernandez AF, Richter J. Changes in the pattern of DNA methylation associate with twin discordance in systemic lupus erythematosus. Genome Res 2010; 20(2): 170-9.

[90] Mizugaki M, Yamaguchi T, Ishiwata S et al. Alteration of DNA methylation levels in MRL lupus mice. Clin Exp Immunol 1997; 110: 265-9.

[91] Balada E, Ordi-Ros J, Vilardell-Tarres M. DNA methylation and systemic lupus erythematosus. Ann N Y Acad Sci 2007; 1108: 12736.

[92] Zhou Y, Lu Q. DNA methylation in T cells from idiopathic lupus and drug-induced lupus patients. Autoimmun Rev 2008; 7: 376-83.

[93] Okada M, Ogasawara H, Kaneko H et al. Role of DNA methylation in transcription of human endogenous retrovirus in the pathogenesis of systemic lupus erythematosus. J Rheumatol 2002; 29: $1678-82$.

[94] Sekigawa I, Ogasawara H, Naito $T$, Kaneko H, Hishikawa T, Hashimoto H. Systemic lupus erythematosus and human endogenous retroviruses. Mod Rheumatol 2003; 13: 107-13.

[95] Ogasawara H, Okada M, Kaneko H, Hishikawa T, Sekigawa I, Hashimoto H. Possible role of DNA hypomethylation in the induction of SLE: relationship to the transcription of human endogenous retroviruses. Clin Exp Rheumatol 2003; 21: 733-8.

[96] Hishikawa $\mathrm{T}$, Ogasawara $\mathrm{H}$, Kaneko $\mathrm{H}$, et al. Detection of antibodies to a recombinant gag protein derived from human endogenous retrovirus clone 4-1 in autoimmune diseases. Viral Immunol 1997; 10(3): 137-47.

(C) Tugnet et al.; Licensee Bentham Open.

This is an open access article licensed under the terms of the Creative Commons Attribution Non-Commercial License (http://creativecommons.org/licenses/by-nc/ $3.0 /$ ) which permits unrestricted, non-commercial use, distribution and reproduction in any medium, provided the work is properly cited 